\title{
Layanan Konseling Kesehatan Untuk Meningkatkan Psychological Well Being Mahasiswa
}

\author{
Lucia Hernawati \\ Fakultas Psikologi, Universitas Katolik Soegijapranata \\ Jl. Pawiyatan Luhur IV/1 Bendan Duwur Semarang \\ email: herna@unika.ac.id
}

\begin{abstract}
Abstrak: Perguruan tinggi bukan hanya tempat mahasiswa mendapatkan pengetahuan secara akademis namun juga non akademis.Perguruan tinggi memiliki tanggung jawab mengantarkan seluruh mahasiswa agar mendapat tantangan dan kesempatan untuk memulai hidupnya menjadi “individu utuh yang memiliki kehidupan yang baik”. Untuk ini perguruan tinggi harus membantu mahasiswa agar lebih menyadari kediriannya, tujuan hidup dan passion nya. Perguruan tinggi harus membantu mahasiswa mengembangkan potensinya agar dapat hidup bahagia (well being khususnya psychological well being). Adapunkepuasan hidup dan kebahagiaan (psychologicalwell being) dapat dipenuhi bila individu dalam keadaan sehat. World Health Organization mendefinisikan sehat sebagai sehat fisik, mental dan sosial. Konseling kesehatan dapat membantu individu mengoptimalkan potensinya. Dinamika upaya secara berkesinambungan mempertahankan kebugaran tubuh, mengelola kognisi dan afeksi untuk memberi makna positif pada pengalaman hidup dan berupaya menyelesakan masalah dalam hidup, serta berinteraksi sosial dengan harmoni dan saling memberikan dukungan pada orang lain membuat individu merasa puas dalam hidup dan bahagia. Tujuan dari kegiatan ini untuk memberikan layanan konseling kesehatan untuk meningkatkan kebahagiaan (psychological well being) mahasiswa. Tiga puluh mahasiswa dari berbagai fakultas di Unika Soegijapranata terlibat dalam aktivitas ini. Dengan mengikuti tiga sesi konseling kesehatan dengan tema kesehatan fisik, mental, dan sosial terjadi peningkatan psychological well being.
\end{abstract}

Abstract: University is not only a place where students get knowledge academically but also non-academically. It must show responsibility to give students the opportunity to have a good life. For this reason, university must help students to be aware of their self, their purpose in life and passion. It must help students develop their potential so they can live happily (well being especially psychological well being). The life satisfaction and happiness (psychological well being) can be fulfilled if the individual is in good health. The World Health Organization defines health as being physically, mentally and socially healthy. Health counseling can help 
individualsoptimize their potential. Continuous efforts to maintain body fitness, manage emotion and thinking ability for giving positive interpretation in life experinces and harmony social interaction and mutual support to others make individuals feel satisfied in life and happy. The purpose of this activity is to provide health counseling services to increase students' psychological well being. Thirty students from various faculties at UnikaSoegijapranata were involved in this activity. By attending three health counseling sessions with the theme of physical, mental, and social health there was an increase in psychological well being.

Keywords: Psychological well being, health counseling

\section{PENDAHULUAN}

Pada saat mahasiswa kuliah di perguruan tinggi terjadi perubahan rutinitas dibandingkan saat sebelum kuliah. Mahasiswa harus beradaptasi pada kehidupan kampus, diantaranya menghadapi tekanan teman sebaya, tekanan akademik, makan terlambat karena jadual kuliah yang padat, kurang tidur karena harus menegerjakan berbagai tugas dari dosen, kondisi fisik yang tidak prima akibat kelelahan fisik dan mental(Ball \& Bax, 2002). Hal serupa ditemukan pada penelitian Aceijas, Waldhausl, Lambert, Cassar, \& Corassa (2017) bahwa mahasiwa kurang beraktivitas fisik, tidak berimbang antara waktu produktif dan rekreasi, mengalami stress karena adanya kompetisi kelas, dan mengalami tekanan teman sekelas dalam mengerjakan tugas kelompok.

Ansari, Labeeb, Moseley, Kotb, ElHoufy (2013) dalam penelitiannya menemukan bahwa mahasiswa pada tingkat perguruan tinggi berada pada periode harus bertanggung jawab pada pilihan-pilihan hidupnya termasuk gaya hidup (life style) yang dijalani. Bergulat dengan gaya hidup sehat versus tidak sehat, keterbatasan finansial versus adanya dukungan finansial, dan adanya interaksi sosial yang harmoni versus kesepian serta harus mampu menyesuaikan diri dengan harapan sosial.

Cairns, Massfeller, \& Deeth (2010) menemukan dalam penelitiannya bahwa masalah yang dihadapi mahasiswa di jaman ini lebih kompleks. Perkembangan teknologi dan era globalisasi memudahkan mahasiswa berkomunikasi dengan siapapun, dapat mengakses informasi dari manapun namun disisi lain membuatnya tidak produktif di bidang akademik. Terjadi fenomena proktrastinasi, fisik kurang bergerak secara memadai, konflik dengan orang lain mewarnai kehidupan mahasiswa. 
Perguruan tinggi bukan hanya tempat mahasiswa mendapatkan pengetahuan secara akademis namun juga non akademis. Perguruan tinggi harus menyiapkan kurikulum yang sesuai dengan program studi masing-masing juga menyiapkan layanan bimbingan dan konseling yang dapat membekali mahasiswa agar berprestasi dalam bidang akademik dan mampu belajar untuk hidup (Gysbers \& Henderson, 2012: $62)$.

Hal serupa diungkapkan Adebowale (2011) bahwa pendidikan adalah landasan dasar bagi pengembangan sebuah bangsa. Karena dalam pendidikan bukan hanya disampaikan materi-materi pengetahuan namun juga membentuk karakter. Khususnya dalam pendidikan tinggi (perguruan tinggi)institusi pendidikan tinggi selain berkewajiban menyampaikan berbagai materi pengetahuan, juga harus membantu mahasiswa yang sedang bergulat dengan masalah pribadi, masalah akademik, dan masalah umum lainnya.

$$
\text { Pingree \& Harward (2014:9) }
$$
menyebutkan bahwa perguruan tinggi memiliki tanggung jawab mengantarkan seluruh mahasiswa agar mendapat tantangan dan kesempatan untuk memulai hidupnya menjadi "individu utuh yang memiliki kehidupan yang baik”. Untuk ini perguruan tinggi harus membantu mahasiswa agar lebih menyadari kediriannya, tujuan hidup dan passion nya. Perguruan tinggi harus membantu mahasiswa mengembangkan potensinya agar dapat hidup bahagia (well being khususnya psychological wel being). Selanjutnya psychological well beingdisingkat PWB.

\section{RUMUSAN MASALAH}

Berdasar wawancara pada pertengahan bulan oktober 2018 di kampus UNIKA Soegijapranata pada sejumlah mahasiswa dari berbagai fakultas di Unika Soegijapranata diperoleh informasi bahwa

pada self scaling dengan rating 1-10 rata-rata memiliki skor 7 pada aspek self acceptance (penerimaan diri), environmental mastery (penguasaan lingkungan), positive relation (hubungan positif dengan orang lain), purpose in life (tujuan hidup), personal growth (pertumbuhan pribadi), autonomy (otonomi) sebagai aspek psychological well being yang dikembangkan Riff tahun 1995.

Pada aspek self acceptance, yang dirasakan menghambat untuk mampu menerima diri sendiri adalah masalah keluarga, merasa direndahkan oleh orang lain, tidak lulus SBMPTN.

Hambatan pada aspek environmental khususnya dalam pemberian kontribusi pada lingkungan sosialnya adalah rasa malas, takut memulai sesuatu yang baru, kawatir ditolak, kurang percaya diri, orang di sekitar 
dirasakan kurang memberi kenyamanan, merasa tidak punya waktu.

Aspek positive relation yang dirasakan menghambat adalah kurang mampu memulai obrolan, ragu-ragu, kurang mampu melakukaan penyesuaian sosial, sulit percaya pada orang lain. Hambatan pada aspek purpose in life adalah belum mampu membuat prioritas, sering mengalami perbedaan antara yang direncanakan dengan kenyataan, lingkungan terutama orangtua kurang mendukung, berprinsip hidup mengalir saja. Aspek personal growth yang menghambat adalah tidak peduli pada pertumbuhan diri sendiri, tidak memahami apa yang diinginkan diri sendiri, tidak disiplin diri dan lebih mengutamakan mood, tidak yakin bisa mengembangkan diri, lingkungan kurang mendukung pertumbuhan diri. Pada aspek autonomy yang menghambat adalah orangtua terlalu banyak mengatur mulai dari makanan yang harus dikonsumsi hingga menentukan pasangan hidup, finansial masih bergantung pada orangtua, adanya tekanan sosial budaya dari masyarakat, ada keinginan untuk mendahulukan yang diharapkan orang lain daripada diri sendiri, suka tergantung pada orang lain.

Berdasar wawancara awal dapat diambil kesimpulan bahwa kepuasan hidup dan kebahagiaan (psychologicalwell being) mahasiswa Strata-1 UNIKA Soegijapranata saat ini masih dalam taraf sedang dan terdapat beberapa hambatan untuk pengembangan self acceptance, environmental mastery, positive relation, purpose in life, personal growth dan autonomy. Dengan demikian mahasiswa Strata-1 UNIKA Soegijapranata perlu diberi bantuan dalam rupa layanan konseling untuk meningkatkan kepuasan hidup dan kebahagiaannya (Psychologicalwell being) dan mampu mengatasi hambatan-hambatan dalam pengembangan well being nya. Kepuasan hidup dan kebahagiaan (Psychologicalwell being) dapat dipenuhi bila individu dalam keadaan sehat. World Health Organization mendefinisikan sehat sebagai sehat fisik, mental dan sosial. Myers \& Sweeney (2008) dalam wellness konselingnya mengembangkan konsep kesehatan yang holistik (sehat fisik, mental, sosial) untuk dapat membantu individu mengoptimalkan potensinya. Dinamika upaya secara berkesinambungan mempertahankan kebugaran tubuh, mengelola kognisi dan afeksi untuk memberi makna positif pada pengalaman hidup dan berupaya menyelesakan masalah dalam hidup, serta berinteraksi sosial dengan harmoni dan saling memberikan dukungan pada orang lain membuat individu merasa puas dalam hidup dan bahagia.

Promosi kesehatan perlu dilakukan di perguruan tinggi agar mahasiswa mendapat 
informasi tentang gaya hidup yang sehat secara holistik (fisik, mental, sosial) dan mengupayakannya pada perilaku riil. Bila mahasiswa memiliki gaya hidup sehat secara holistik diharapkan dapat lebih produktif dalam bidang akademik. Selanjutnya dapat menjalani studinya dengan lebih bahagia (Brener \& Gowda, 2001). Dalam jangka panjang akan terbentuk komunitas yang sehat. Dipertemukan berbagai kebutuhan individu-individu dalam komunitas dalam cara kongruen dengan nilai yang jelas: meliputi kebebasan, terdapat pertumbuhan pribadi, sehat, peduli, simpatik, akuntabilitas, transparan, dan responsif.

\section{METODE}

Bekerjasama dengan wakil dekan III berbagai fakultas di UNIKA Soegijapranata, direkomendasikan mahasiswa yang perlu mendapat layanan konseling kesehatan. Pada mahasiswa tersebut diberikan skala psychological well being(skala PWB) untuk diisi. Mahasiswa yang memiliki skor rendah diberi kesempatan mendapat layanan konseling kesehatan. Total 30 orang dari berbagai fakultas yang memiliki skor rendah pada skala PBW mendapat layanan konseling kesehatan untuk meningkatkan PWB nya. Dilakukan 3 sesi konseling dengan materi sebagai berikut: $\underline{\text { Konseling kesehatan sesi } 1}$

Disampaikan konsep konseling kesehatan dan perlunya meningkatkan psychological well being(PWB). Adapun PWB adalah keadaan perkembangan potensi nyata individu yang ditandai dengan karakteristik dapat menghargai dirinya sendiri dengan positif termasuk kesadaran akan keterbatasan diri pribadi (selfacceptance), mampu membangun dan menjaga hubungan baik dan hangat dengan orang lain (positiverelationship with others), mampu menciptakan konteks lingkungan sekitar sehingga bisa memuaskan kebutuhan dan hasrat diri individu sendiri untuk memberi kontribusi pada lingkungan sosialnya (environmental mastery), mampu membangun kekuatan individu dan kebebasan personal (autonomy), memiliki dinamika pembelajaran sepanjang hayat dan keberlanjutan mengembangkan kemampuan diri (personal growth) serta memiliki tujuan hidup yang menyatukan usaha dan tantangan yang dihadapi (purpose in life).

PWB dicapai dengan mendapat pelayanan konselingkesehatan. Konseling kesehatan awalnya disebut wellness konseling. Dikembangkan Myers \& Sweeney tahun 2008 berdasar konsep Adler tentang individual psychology. Adler menamai teori yang dikembangkannya dengan Individual Psychology yang berarti indivisible (fenomena individual yang 
merupakan kesatuan). Individu tidak bisa dipahami hanya sebagian saja atau per bagian namun harus secara keseluruhan. Adler percaya bahwa secara alamiah perilaku manusia bersifat holistik, berkorelasi satu dengan lainnya, terarah dan memiliki tujuan tertentu. Disebutkan indivisble self atau self yang utuh dan tak terbagi berada pada posisi pusat. Antara spirit, psikis dan fisik merupakan satu kesatuan dan saling memengaruhi. Self menjadi pusat diri individu.

Dalam realisasinya self memancar keluar menjadi: pertama, kemampuan creative. Kedua, kemampuan melakukan coping.Ketiga, kemampuan bersosialisasi yang memungkinkan individu untuk menggalang relasi sosial dalam keluarga dan lingkungan sosial yang lebih luas.Keempat, kemampuan memahami bahwa manusia bukan hanya terdiri dari hal material namun menjadi bagian dari dunia seisinya.Kelima, kemampuan untuk mengembangkan aspek physical.

Pada konseling kesehatan sesi 1 ini mahasiswa disadarkan perlunya mengembangkan PWB dengan cara menyadari perlunya meningkatkan kemampuan coping, kreatifitas dalam menyelesaikan masalah, menggalang relasi harmonis dengan orang lain, pemahaman esensial bahwa manusia adalah bagian dari dunia seisinya dan meningkatkan kebugaran fisik.

Sesi 1 ini diakhiri dengan pengisian alat ukur wellness inventory yang telah diadaptasi ke dalam bahasa Indonesia. Melalui self-skorring, mahasiswa dapat memahami profil kesehatannya sebelum mendapat layanan konseling kesehatan. Mahasiswa diminta memperhatikan dimensi kesehatan yang memiliki skor terendah. Dimensi inilah yang harus ditingkatkan melalui konseling kesehatan. Dipilih 1 dimensi saja dengan asumsi bahwa self tak terbagikan. Kelima dimensi kesehatan akan berhubungan satu sama lain. Meningkatkan 1 dimensi akan mempengaruhi 4 dimensi lainnya.Sesi pertama ini diakhiri dengan pembuatan aktivitas harian selama 3 hari ke depan dengan merancang perilaku riil untuk meningkatkan dimensi kesehatan yang masih rendah. Selanjutnya mahasiswa diminta menjalankan apa yang telah direncanakan sebagai tugas rumah. Tak lupa mahasiswa diminta mencatat hal-hal yang mendukung keberhasilan dan penyebab kegagalan tidak menjalakan apa yang telah direncanakan.

\section{$\underline{\text { Konseling kesehatan sesi } 2}$}

Dilaksanakan 3 hari berikutnya dari konseling sesi 1. Pada konseling sesi 2, dibentuk kelompok kecil secara acak yang berisi 5 orang. Dalam kelompok kecil ini, 
tiap mahasiswa diajak untuk membuat evaluasi terhadap pelaksanaan aktivitas yang telah dilaksanakan dan lebih memahami diri (kelemahan dan kelebihan diri), komitmen diri melalui sharring, take, give

Selajutnya mahasiswa diajak untuk memahami lebih lanjut tentang pengembangan aspek kreativitas, coping, social, esensial, dan fisikal sebagai lima dimensi kesehatan holistik. Sehingga dapat membuat perencanaan yang lebih realistik untuk tujuh hari kedepan. Setelahnya diminta untuk menjalankan sebagai tugas rumah. Dalam menjalankan semua perencanaan, mahasiswa diminta mencatat hal-hal yang mendukung keberhasilan dan penyebab kegagalan tidak menjalankan apa yang telah direncanakan.

\section{$\underline{\text { Konseling sesi } 3}$}

Dilaksanakan 7 hari berikutnya dari konseling sesi 2. Mahasiswa diminta masuk pada kelompok kecil yang telah dibentuk pada sesi konseling sebelumnya. Evaluasi selama tujuh hari pelaksanaan perencanaan aktivitas kesehatan dilakukan. Disamping mahasiswa diajak untuk lebih memahami pola perilakunya, komitmen menjalankan apa yang telah direncanakan dan dampak peningkatan kesehatan yang telah dirasakan melalui sharring, take, give
Pada akhir sesi 3 ini mahasiswa diminta mengisi skala PWB. Self-skorring dilakukan. Lalu dibandingkan dengan pengisian awal sebelum diberikan konseling kesehatan untuk mengetahui apakah ada peningkatan PWB setelah diberikan konseling kesehatan atau tidak.

Sebelum sesi konseling ini diakhiri, mahasiswa dimotivasi untuk meneruskan gaya hidup sehat yang sudah dijalankan selama 10 hari.

\section{HASIL DAN PEMBAHASAN}

Perkembangan yang dirasakan peserta dari ketiga sesi adalah sebagai berikut:

Pada konseling kesehatan satu, mahasiswa mendapat pencerahan perlunya meningkatkan PWB dan dapat dicapai dengan konseling kesehatan. Disamping itu peserta memahami diri tentang dimensi kesehatan mana yang masih perlu ditingkatkan pada dirinya dan memikirkan cara meningkatkannya serta menjalankan perencanaanya untuk tiga hari kedepan. Pada umumnya akan meningkatkan aspek fisikal, sosial, dan kreatif.

Pada sesi dua konseling kesehatan, mahasiswa mengevaluasi aktivitas yang telah direncanakan dan dijalankan selama tujuh hari. Dari sharring kelompok, ditemukan bahwa peserta merasa lebih sehat, mood lebih positif, lebih semangat mengikuti perkuliahan, dan lebih mengenali 
diri. Walaupun masih ada diantara peserta yang melakukan self defence, mengatakan bahwa kegiatan terlalu banyak sehingga tidak bisa menjalankan perencanaan yang telah disusun, dan ada pula yang kurang memiliki komitmen yang tinggi, mengatakan bahwa sudah berusaha tapi belum mampu menjalankan perencanaan yang telah disusun. Selajutnya mahasiswa diajak untuk memahami lebih lanjut tentang pengembangan aspek kreativitasdalam menyelesaikan masalah, mengupayakan agar saat menghadapi masalah dengan problemfocusedcoping, mengupayakan relasi harmoni dalam bersosialisasi, meningkatkan pemahaman esensial dalam hidup, dan meningkatkan kebugaran fisikal sebagai lima dimensi kesehatan holistik. Sehingga dapat membuat perencanaan yang lebih realistik untuk tujuh hari kedepan.

Pada konseling sesi 3 mahasiswa mengevaluasi aktivitas yang telah direncanakan dan dijalankan selama 7 hari untuk memahami komitmen diri dalam menjalankan perencanaan yang telah dibuat, dan pola perilaku. Dari sharring kelompok diketahui bahwa peserta merasa lebih bugar tubuhnya, komitmen menjalankan perencanaan lebih tinggi, lebih percaya diri, lebih mampu bersosialisasi, lebih mengenal diri sendiri.

Berdasarkan hasil pengisian skala PWB pada umumnya (95\%) mahasiswa merasa lebih mampu menerima diri apa adanya;lebih mampu membangun dan menjaga hubungan baik dan hangat dengan orang lain; lebih mampu menciptakan konteks lingkungan sekitar sehingga bisa memuaskan kebutuhan dan hasrat diri individu sendiri untuk memberi kontribusi pada lingkungan sosialnya; lebih mampu membangun kekuatan individu dan kebebasan personal; lebihmampu melakukan dinamika pembelajaran sepanjang hayat serta keberlanjutan lebih mampu mengembangkan kemampuan diri sertalebih memiliki tujuan hidup yang menyatukan usaha dan tantangan yang dihadapi.

Dengan demikian konseling kesehatan telah mampu meningkatkan PWB mahasiswa.

\section{SIMPULAN}

1. Layanan konseling kesehatan dapat meningkatkan psikological well being mahasiswa

2. Monitoring dan dukungan secara berkesinambungan membuat mahasiswa merasa diperhatikan dan memiliki motivasi untuk terus membuat perencanaan hidup sehat serta menjalankannya. 


\section{DAFTAR PUSTAKA}

Acaijas, C., Waldhausl, S., Lambert, N., Cassar, S., \& Corassa R.B. (2017). Determinants of Health-Related Lifetyles among University Students. Perspectives in Public Health, 137(4) 227-236

Adebowale, T.A. (2011). Perceived Availability of Guidance and Counseling Servis among Tertiary Institute Students in Selected SouthWest University in Nigeria. LifePsychology, 19(1)360-374

Ansari, W.E, Labeeb, S., Moseley, L., Kotb, S., El-Houfy, A. (2013). Physical and Psychological Well Being of Universitas Students:Survey of Eleven Faculty in Egyp. International Journal of Preventive Medicine, 4(3), 293-310

Ball, S. Bax, A . (2002). Self care in medical education: effectiveness of health-habit interventions for first year medical students, Journal ofAcademic Medicine, 77(9), 911-917

Brener, N.D., \& Gowda, V.R. (2001). US College Students’ Report of Receiving Health Information on College Campuses. Journal of American College Health, 49(5) 223-228
Cairns, S.L., Massfeller, H.F., \& Deeth, S.C. (2010). Why do Postsecondary Students Seek Counseling? Canadian Journal of Counselling 44(1)34-50. ISSN 0826-3893

Gysbers, Norman, C \& Henderson, Patricia. (2012).Developing \& Managing Your School Guidance \& Counseling Program, USA: American Counseling Association

Myers J.E, \&Sweeney. T.J. (2008). Wellness Counseling: The Evidence Base for Practice. Journal of Counseling and Development: JCD; 86,482-493

Pingree \& Harward. (2014).Bringing Theory to Practice. The Psychological Well Being and Flourishing of Students, Liberal Education 